\title{
Prevalence and clinical impact of VIral Respiratory tract infections in patients hospitalized for Community-Acquired Pneumonia: the VIRCAP study
}

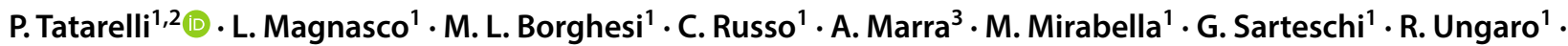 \\ C. Arcuri ${ }^{4}$ - G. Murialdo ${ }^{3}$. C. Viscoli ${ }^{1}$ - V. Del Bono ${ }^{5}$ - L. A. Nicolini ${ }^{1}$
}

Received: 7 April 2019 / Accepted: 21 November 2019 / Published online: 30 November 2019

(c) Società Italiana di Medicina Interna (SIMI) 2019

\begin{abstract}
Prevalence and clinical impact of viral respiratory tract infections (VRTIs) on community-acquired pneumonia (CAP) has not been well defined so far. The aims of this study were to investigate the prevalence and the clinical impact of VRTIs in patients with CAP. Prospective study involving adult patients consecutively admitted at medical wards for CAP and tested for VRTIs by real-time PCR on pharyngeal swab. Patients' features were evaluated with regard to the presence of VRTI and aetiology of CAP. Clinical failure was a composite endpoint defined by worsening of signs and symptoms requiring escalation of antibiotic treatment or ICU admission or death within 30 days. 91 patients were enrolled, mean age $65.7 \pm 10.6$ years, $50.5 \%$ female. 62 patients (68.2\%) had no viral co-infection while in 29 patients (31.8\%) a VRTI was detected; influenza virus was the most frequently identified (41.9\%). The two groups were similar in terms of baseline features. In presence of a VRTI, pneumonia severity index (PSI) was more frequently higher than 91 and patients had received less frequently pre-admission antibiotic therapy (adjusted OR 2.689, 95\% CI 1.017-7.111, $p=0.046$; adjusted OR 0.143, 95\% CI $0.030-0.670, p=0.014$ ). Clinical failure and antibiotic therapy duration were similar with regards to the presence of VRTI and the aetiology of CAP. VRTIs can be detected in almost a third of adults with CAP; influenza virus is the most relevant one. VRTI was associated with higher PSI at admission, but it does not affect patients' outcome.
\end{abstract}

Keywords Viral respiratory tract infections $\cdot$ Community-acquired pneumonia $\cdot$ Influenza $\cdot$ Pneumonia severity index

\section{Introduction}

P. Tatarelli

paolatatarelli@gmail.com

1 Division of Infectious Diseases, Department of Health Sciences (DiSSal), San Martino Polyclinic Hospital and IRCCS, University of Genoa, Via Pastore, 1, 16132 Genoa, Italy

2 Department of Infectious Diseases, Ospedale Santa Maria Delle Croci, Ravenna, Italy

3 Second Clinic of Internal Medicine, Department of Internal Medicine, San Martino Polyclinic Hospital and IRCCS, University of Genoa, Genoa, Italy

4 Department of Health Sciences (DiSSal), University of Genoa, Genoa, Italy

5 Infectious Diseases Unit, Azienda Ospedaliera S. Croce E Carle, Cuneo, Italy
Community-acquired pneumonia (CAP) is a common cause of hospitalisation and one of the main infectious causes of mortality worldwide [1-3]. In Europe, up to $32 \%$ of patients with CAP are hospitalized every year and the CAP mortality rate reaches $9.1 \%$ [4, 5]. Streptococcus pneumoniae is the main aetiologic agent of CAP, being responsible for two thirds of cases, but other pathogens such as Haemophilus influenzae, Moraxella catarrhalis, Chlamydophila pneumoniae, Mycoplasma pneumonia, Legionella spp. and Staphylococcus aureus are frequently involved [2].

Respiratory viruses (which include rhinovirus, metapneumovirus, adenovirus, coronavirus, respiratory syncytial virus, influenza and parainfluenza viruses) have increasingly been recognized as causes of respiratory tract infections [6]. Whilst epidemiology and clinical features of viral respiratory tract infections (VRTIs) were mainly explored in children and outpatients $[7,8]$, a few data show increasing 
prevalence rates also in hospitalized patients, particularly in elderly and in presence of comorbidities such as asthma, chronic obstructive pulmonary disease or immunosuppression [9-11].

The recent development and diffusion of nucleic acid amplification tests (NAATs) on respiratory samples have improved the ability to diagnose multiple upper and lower VRTIs, possibly affecting prevalence estimates [12]. Compared to classical microbiological techniques, NAATs allow earlier and more sensitive diagnosis [13, 14], providing clinical advantages in terms of length of hospitalization, infection control and antibiotics use [15, 16]. However, in non-intubated hospitalized adults with CAP, lower respiratory tract sampling is not easy to obtain and VRTI diagnosis usually relies on nose-throat swabs, affecting the clinical significance of identified viruses [17].

Beyond viral CAP, upper VRTIs predispose to pulmonary bacterial infections as they cause bronchoconstriction, increase mucus production [18-20], decrease the efficiency of muco-ciliary clearance [21], damage respiratory mucosa and cause leukocytes dysfunction [19]. Data from both in vitro animal models and clinical experiences have demonstrated that influenza and other VRTIs are risk factors for pneumococcal pneumonia, both in adult and paediatric population [22-26]. In spite of improved viral diagnosis and well-known pathophysiology, data on the clinical impact of VRTIs on CAP are controversial and some authors reported higher mortality rates [17].

The primary aim of this study was to investigate the prevalence of VRTIs in a prospective cohort of adult patients hospitalized at medical wards for CAP; the secondary aims were to describe patient's features and outcomes according to the presence of VRTI and the aetiology of CAP.

\section{Methods}

\section{Study cohort}

We prospectively enrolled all adult patients consecutively admitted for CAP and tested for VRTIs at two medical wards (Infectious Diseases and Internal Medicine Unit) of Policlinico San Martino-IRCCS, Genoa, Italy, from November 2016 to February 2018. Patients having nosocomial pneumonia (i.e. developed at least $48 \mathrm{~h}$ after hospital admission) and those diagnosed with opportunistic pulmonary infection were excluded.

\section{Definitions}

CAP was defined as acute lower respiratory tract infection characterized by the presence of two or more signs and symptoms (among fever, cough, dyspnoea, pleuritic pain, crackles or bronchial breath at pulmonary auscultation), associated with at least one among (a) radiological findings (opacity or infiltrate at radiography or computed tomography interpreted as pneumonia by the attending physician), (b) serum levels of inflammatory markers above normal values and (c) neutrophilic leucocytosis, in patients hospitalized no longer than $48 \mathrm{~h}$ [1].

The definitive bacterial aetiology for CAP was defined as (1) identification of an aetiological agent in the blood and/ or pleural fluid and/or bronchoalveolar lavage (with $>10^{5}$ colony-forming units/ml; (2) detection of Legionella pneumophila spp. or S. pneumoniae antigen in the urine; (3) positive PCR for Legionella spp., M. pneumoniae or Chlamydia spp. on pharyngeal swab and/or bronchoalveolar lavage. Presumptive bacterial aetiology was defined by positive culture on sputum or positive PCR for H. influenzae, Bordetella spp. or S. pneumoniae on pharyngeal swab [27] In case of VRTI, $\mathrm{CAP}$ was considered of possible viral origin (or mixed origin in the presence of concomitant bacteria identification).

Antibiotic treatment escalation was defined as enhancing the anti-bacterial spectrum switching to or adding another molecule after at least a full $48 \mathrm{~h}$-course of an initial, inhospital treatment, with the exclusion of targeted treatment. Clinical failure was defined as (1) antibiotic treatment escalation; (2) worsening of signs and symptoms of pneumonia requiring ICU admission; (3) death within 30 days. In addition, the total time of antibiotic exposure (TTA) was calculated.

\section{Study procedures}

For each patient, the following information was collected: demographic data (i.e. age, gender, country of origin), comorbidities (i.e. concomitant pulmonary or extrapulmonary diseases), chronic therapies for concomitant diseases, influenza and S. pneumoniae vaccination status, antibiotic therapy, results of radiological investigations (i.e. chest $\mathrm{X}$-ray or computed tomography), biochemical tests (white blood cells, C reactive protein and procalcitonin) and outcome.

For every patient, the presence of VRTIs was ascertained with multiplex real time-polymerase chain reaction (RTPCR) on pharyngeal swab (Allplex TM Respiratory Panel Assay, Seegene, Seoul, South Korea) [28]. On the same sample, RT-PCR for S. pneumoniae, H. influenzae, C. pneumoniae, $M$. pneumoniae and B. pertussis was performed.

Microbiological findings from conventional tests (i.e. blood culture, sputum and broncoalveolar fluid culture, $S$. pneumoniae and L. pneumophila urine antigen detection, serology for intra-cellular bacteria) were also analysed. Given the non-interventional nature of the study, bronchoalveolar lavage for microbiological tests was not 
systematically performed, but nonetheless available results were collected.

CURB-65 score $>2$ and Pneumonia Severity Index (PSI) class IV-V (i.e. $\geq 91$ ) at admission $[29,30]$ were evaluated to assess CAP severity at clinical presentation.

Being an observational study, treatment was decided by the physician in charge according to the usual standard of care. Clinical outcome, according to the aforementioned definitions, was recorded for each patient.

Before analysing the study results, all the cases were reviewed by independent observers who verified their correct classification in the study definitions.

\section{Statistical analysis}

Statistical analysis was mainly descriptive. Patients' features, pneumonia severity scores were evaluated according to the concomitant presence of a VRTI and aetiology of CAP. Categorical variables were compared with Chi-square test or Fisher's exact test, when applicable. Continuous variables were compared with Mann-Whitney and ANOVA tests. A value of $p<0.05$ was considered statistically significant. Variables significantly $(p<0.05)$ associated with the presence of a VRTI and the aetiology of CAP at previously mentioned tests were evaluated by multivariate logistic regression models. The same statistical tests were used to evaluate if the presence of a VRTI, the aetiology of CAP and patients' features were associated with outcome variables, such as clinical failure and TTA.

Statistical analysis was carried out using SPSS.

\section{Ethics}

The study protocol was approved by the Local (Ligurian Region) Ethic Committee. Upon enrolment all patients signed a dedicated informed consent.

\section{Results}

\section{Study cohort}

During the study period, 99 patients were admitted for CAP. Of them, 8 were excluded because of the diagnosis of opportunistic pulmonary infection $(n=3)$ and missed testing for VRTIs $(n=5)$. Thus, 91 patients with CAP and tested for VRTI by pharyngeal swab were finally included in our study (Fig. 1).

Patients' characteristics at baseline are reported in Table 1 . Briefly, mean age was $65.7 \pm 10.6$ years; 46 (50.5\%) of them were female. Overall, 86 patients $(94.5 \%)$ were of Caucasian origin. The majority of CAP $(75 / 91,82.4 \%)$ occurred during autumn/winter. Cardiovascular disease was

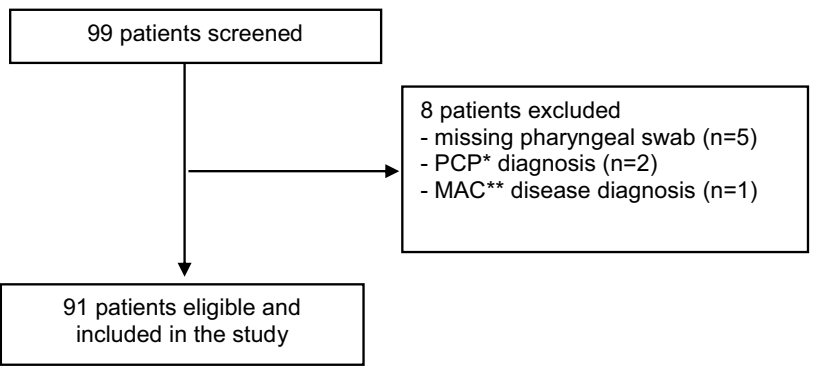

Fig. 1 Enrolment of patients. Asterisk, Pnemocystis carinii pneumonia. Double asterisk, Mycobacterium avium complex

Table 1 Baseline characteristics of the study population

\begin{tabular}{|c|c|}
\hline & Patients $n=91(\%)$ \\
\hline Age, mean $\pm S D$, years & $65.7 \pm 10.6$ \\
\hline Gender, female & $46(50.5)$ \\
\hline Race, Caucasian & $86(94.5)$ \\
\hline Hospitalized in autumn/winter & $75(82.4)$ \\
\hline Smoking, yes & $47(51.6)$ \\
\hline Alcohol consumption, yes ${ }^{\mathrm{a}}$ & $15(16.5)$ \\
\hline \multicolumn{2}{|l|}{ Comorbidities } \\
\hline Cardiovascular disease & $45(49.5)$ \\
\hline Respiratory disease & $20(22)$ \\
\hline Onco-haematological disease & $16(17.6)$ \\
\hline Chronic kidney disease & $14(15.4)$ \\
\hline Diabetes & $11(12.1)$ \\
\hline Chronic liver disease & $7(7.7)$ \\
\hline HIV infection & $6(6.6)$ \\
\hline Rheumatologic disease & $6(6.6)$ \\
\hline Presence of at least 2 comorbidities, yes & $68(74.7)$ \\
\hline Treatment with immunosuppressive drugs, yes & $8(8.8)$ \\
\hline Influenza vaccination ${ }^{\mathrm{b}}$ & $16(17.6)$ \\
\hline Pneumococcal vaccination $^{\mathrm{c}}$ & $8(2.2)$ \\
\hline \multicolumn{2}{|l|}{ CURB-65 } \\
\hline $0-1$ & $54(59.3)$ \\
\hline 2 & $24(26.4)$ \\
\hline$\geq 3$ & $13(14.3)$ \\
\hline \multicolumn{2}{|l|}{ PSI } \\
\hline Class I-II & $31(34.1)$ \\
\hline Class III & $13(14.3)$ \\
\hline Class IV/V & $47(51.6)$ \\
\hline Pre-admission antibiotic therapy & $24(26.4)$ \\
\hline \multicolumn{2}{|l|}{ Etiology of CAP } \\
\hline Bacterial etiology & $19(20.9)$ \\
\hline Possible viral etiology & $20(23.1)$ \\
\hline Possible mixed etiology & $8(8.8)$ \\
\hline Unknown & $43(47.3)$ \\
\hline
\end{tabular}

PSI pneumonia severity index, $S D$ standard deviation

${ }^{\text {a }}$ Missing data in $4.4 \%$ of patients

${ }^{\mathrm{b}}$ Missing data in $23.1 \%$ of patients

${ }^{\mathrm{c}}$ Missing data in $19.8 \%$ of patients 
the most common comorbidity (45/91, 49.5\%), followed by respiratory $(20 / 91,22 \%)$ and onco-haematological disease (16/91, 17.6\%). Mortality risk, as assessed by CURB-65 and PSI score, was increased in $13(14.3 \%)$ and 47 (51.6\%) patients, respectively.

\section{Microbiological results}

Overall, at least one virus was detected by RT-PCR on pharyngeal swab in 29 patients $(31.9 \%, 95 \%$ CI $22.3-41.4 \%)$. A single virus was isolated in all but 2 cases. Influenza was the most frequently identified virus (13/31, 41.9\%; type A in 9 and type B in 4), followed by rhinovirus $(6 / 31,19.4 \%)$, respiratory syncytial virus $(5 / 31,16.1 \%)$, parainfluenza viruses $(4 / 31,12.9 \%)$, coronavirus $(2 / 31,6.5 \%)$ and adenovirus $(1 / 31,3.2 \%)$.

At least one bacterium was documented in 27 patients (30\%) with CAP. The most frequently identified bacterium was $S$. pneumoniae ( $n=16,53.3 \%$ ), followed by $H$. influenzae $(n=4,13.4 \%)$ (Table 2). Bacterial diagnostic samples considered were sputum $(n=13)$, blood $(n=6)$, urine $(n=6)$ and bronchoalveolar lavage $(n=2)$. Nine sputum samples were collected in patients without pre-hospital antibiotic treatment.

Of the 27 definitive/presumptive bacterial CAP, 8 (30\%) were found with a concomitant VRTIs, thus they were possibly caused by mixed viral and bacterial infection. Influenza virus was identified in 4 (virus $A=3$, virus $B=1$ ), rhinovirus in 2, parainfluenza virus in 1 , rhinovirus and parainfluenza virus in 1 case. In 21 cases, viruses were the only pathogens identified and were thus considered as possible causes of CAP. The remaining 43 cases were considered of unknown aetiology because neither bacteria nor viruses were isolated.

Distribution of viral and bacterial pathogens identified is summarized in Table 2.

\section{Analysis according to the presence of VRTI and aetiology of CAP}

Comparing patients with and without VRTI, no statistically significant differences were found in terms of age, gender, origin, smoking and alcohol habits, influenza and S. pneumoniae vaccination status, number and type of comorbidities, modes of admission to hospital, CURB-65 score at admission, presence of bacteraemia, pneumonia radiological features or interval between onset of symptoms and hospital arrival (Table 3 ). VRTIs were slightly more frequently diagnosed in autumn and winter, although difference was not statistically significant $(93.1 \%$ vs $77.4 \%, p=0.081)$. In presence of VRTIs, PSI at admission was more frequently higher than $91(20 / 29,69 \%$, vs $27 / 62,43.5 \%, p=0.027)$ and patients received less frequently pre-admission antibiotic therapy $(2 / 29,6.9 \%$, vs $22 / 62,25.5 \%, p=0.004)$. Including both these variables in a multivariate model, they remained statistically associated to the presence of VRTI (adjusted OR 2.689, 95\% CI 1.017-7.111, $p=0.046$; adjusted OR 0.143, $95 \%$ CI 0.030-0.670, $p=0.014$, respectively) (Table 3 ).

Patients' features were also evaluated with regards to the aetiology of CAP after exclusion of those patients with unknown aetiology. Bacterial (both diagnosed with definitive and presumptive criteria), possibly viral and mixed CAPs were similar in terms of demographic and radiologic features, immunosuppressive status, CURB and PSI score at admission $(p>0.05)$.

\section{Treatment and outcome}

Overall, 24 patients $(27.5 \%)$ received home antibiotic therapy before hospital admission, whilst the remaining patients received first-line antibiotic treatment only thereafter.

In-hospital antibiotic treatment included a beta-lactam in 78 cases (86\%). Of them, 26 (33\%) were treated with piperacillin/tazobactam. Antibiotics active against intracellular bacteria were used in 39 cases ( 25 macrolides, 22 of whom in association with beta-lactams, and 15 fluoroquinolones, 14 of whom as monotherapy).

With regard to antiviral treatment, 9 patients received empirical treatment with oseltamivir, that was early withdrawn in 4 patients who had no confirmed influenza infection by PCR. Ribavirin, after a thorough assessment of risk-benefit analysis, was not administered in any of the 5 patients ( 2 with underlying hematologic malignancies) with respiratory syncytial virus-B infection.

Overall, clinical success was recorded in 72 patients (79\%). Among the 19 patients who experienced clinical failure, 17 required antibiotic escalation (involving an antiMRSA agent in 6 cases), of whom 3 required invasive ventilation and Intensive Care Unit admission. Three patients died. Of them, the first was a 73-year old man with $S$. pneumoniae infection who died in ICU, the second a 51-year old HIV-positive man with respiratory and cardiovascular disease who developed Pseudomonas aeruginosa pneumonia and the third a 91-year old man with myelodysplastic syndrome and chronic kidney disease with a lobar pneumonia and rhinovirus identified on pharyngeal swab.

Clinical failure was not influenced by the presence of VRTI and aetiology of CAP. The only variable associated to clinical failure was baseline PSI higher than 91 (OR 3.31, 95\% CI $1.08-10.16, p=0.036$ ). TTA was similar irrespective to the presence of VRTI (mean \pm SD $11.3 \pm 4.0$ versus $12.3 \pm 6.4$ days, $p=0.55$, in patients with and without VRTI, respectively) and aetiology of CAP $(14.55 \pm 1.61$ versus $12.13 \pm 1.52$ versus $11.54 \pm 0.83$ versus $11.42 \pm 0.93$ days in bacterial, mixed, viral and unknown aetiology CAP, respectively, $p=0.3$ ). No other collected variables were associated to TTA. 


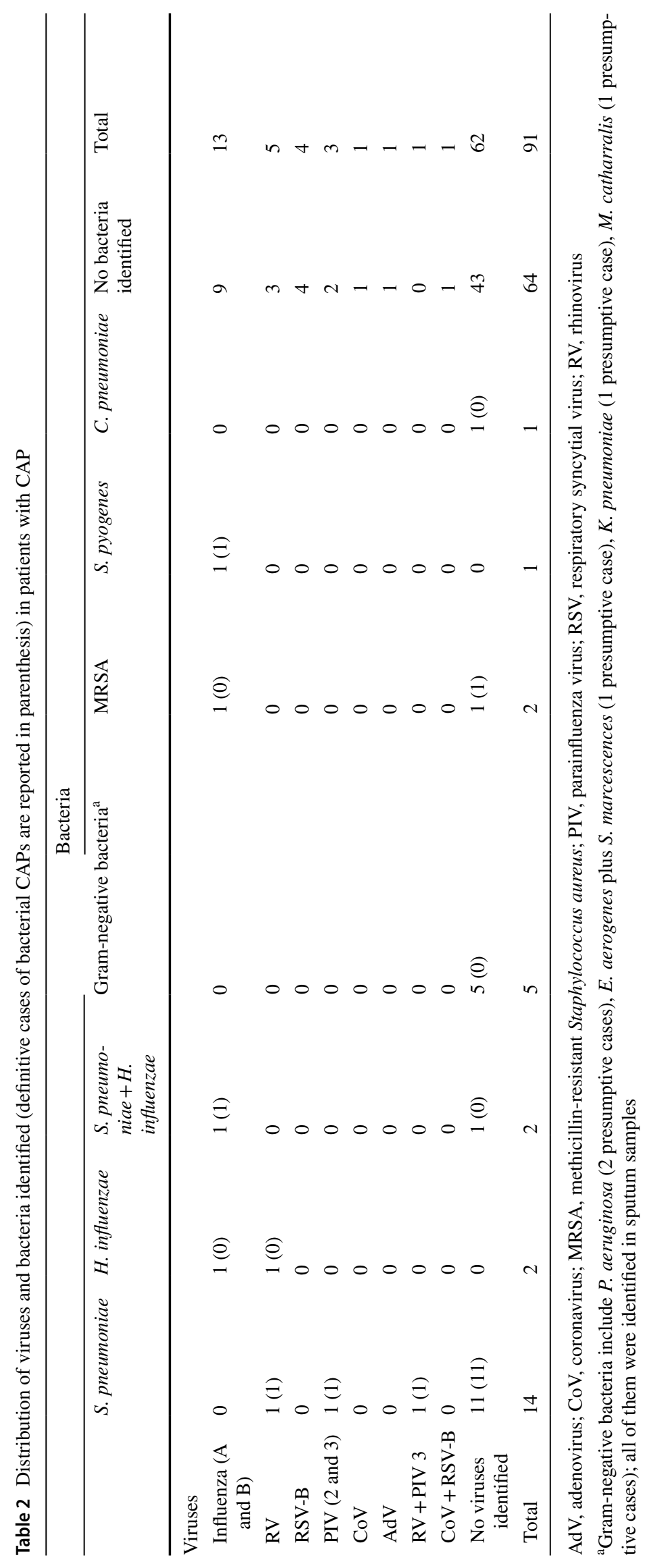


Table 3 Univariate and multivariate analysis of baseline features of patients with and without viral respiratory tract infection

\begin{tabular}{|c|c|c|c|c|c|}
\hline \multirow[t]{2}{*}{ Characteristics } & \multirow[t]{2}{*}{ CAP $(n=62)$} & \multirow[t]{2}{*}{ CAP + VRTI $(n=29)$} & \multirow[t]{2}{*}{$p$ value } & \multicolumn{2}{|c|}{$\begin{array}{l}\text { Multivariate logistic } \\
\text { regression analysis }\end{array}$} \\
\hline & & & & $\operatorname{adjOR}(95 \% \mathrm{CI})$ & $p$ value \\
\hline Age, years, Mean \pm SD & $63.8 \pm 20.3$ & $69.7 \pm 21.3$ & 0.21 & & \\
\hline \multicolumn{6}{|l|}{$\operatorname{Sex} n(\%)$} \\
\hline Male & $31(50)$ & $14(48.3)$ & 1.0 & & \\
\hline Female & $31(50)$ & $15(51.7)$ & & & \\
\hline \multicolumn{6}{|l|}{ Ethnic origin, $n(\%)$} \\
\hline Caucasian & $59(95.2)$ & $27(93.1)$ & 0.65 & & \\
\hline Not-Caucasian & $3(4.8)$ & $2(6.9)$ & & & \\
\hline \multicolumn{6}{|l|}{ Season at admission, $n(\%)$} \\
\hline Spring-Summer & $14(22.6)$ & $2(6.9)$ & 0.65 & & \\
\hline Autumn-Winter & $48(77.4)$ & $27(93.1)$ & & & \\
\hline \multicolumn{6}{|l|}{ Smokers, $n(\%)$} \\
\hline Yes & $34(54.8)$ & $13(44.8)$ & 0.36 & & \\
\hline No & $2540.3)$ & $15(51.7)$ & & & \\
\hline Missing & $3(4.8)$ & $1(3.4)$ & & & \\
\hline \multicolumn{6}{|l|}{ Alcohol consumer, $n(\%)$} \\
\hline Yes & $11(17.7)$ & $4(13.8)$ & 0.77 & & \\
\hline No & $47(75.8)$ & $25(86.2)$ & & & \\
\hline Missing & $4(6.5)$ & $0(0)$ & & & \\
\hline \multicolumn{6}{|l|}{ Influenza vaccination, $n(\%)$} \\
\hline Yes & $11(17.7)$ & $5(17.2)$ & 1.0 & & \\
\hline No & $36(58.1)$ & $18(62.1)$ & & & \\
\hline Missing & $15(24.2)$ & $6(20.7)$ & & & \\
\hline \multicolumn{6}{|l|}{ S. pneumoniae vaccination $n(\%)$} \\
\hline Yes & $1(1.6)$ & $1(3.4)$ & 1.0 & & \\
\hline No & $48(77.4)$ & $23(79.3)$ & & & \\
\hline Missing & $13(21.0)$ & $5(17.2)$ & & & \\
\hline$\geq 2$ comorbidities, $n(\%)$ & $45(49.5)$ & $23(33.8)$ & 0.61 & & \\
\hline Respiratory disease & $12(19.4)$ & $8(27.6)$ & 0.42 & & \\
\hline Cardiovascular disease & $30(48.4)$ & $15(51.7)$ & 0.82 & & \\
\hline Diabetes & $7(11.3)$ & $4(13.8)$ & 0.74 & & \\
\hline Kidney disease & $11(17.7)$ & $3(10.3)$ & 0.54 & & \\
\hline Liver disease & $7(11.3)$ & $0(0.0)$ & 0.09 & & \\
\hline HIV infection & $5(8.1)$ & $1(3.4)$ & 0.66 & & \\
\hline Onco-haematological disease & $8(12.9)$ & $8(27.6)$ & 0.14 & & \\
\hline Immunosuppressive therapy & $4(6.5)$ & $4(13.8)$ & 0.26 & & \\
\hline Rheumatologic disease & $3(4.8)$ & $3(10.3)$ & 0.38 & & \\
\hline \multicolumn{6}{|l|}{ Admission mode, $n(\%)$} \\
\hline By Emergency Department & $49(53.8)$ & $24(26.4)$ & 0.78 & & \\
\hline $\begin{array}{l}\text { Others (sent by general practitioner, specialist doctor or emer- } \\
\text { gency medical service) }\end{array}$ & $13(14.3)$ & $5(5.5)$ & & & \\
\hline \multicolumn{6}{|l|}{ CURB-65 $\geq 3, n(\%)$} \\
\hline Yes & $10(16.1)$ & $3(10.3)$ & 0.54 & & \\
\hline No & $52(83.9)$ & $26(89.7)$ & & & \\
\hline \multicolumn{6}{|l|}{$\mathrm{PSI} \geq 91, n(\%)$} \\
\hline Yes & $27(43.5)$ & $20(69.0)$ & 0.027 & $2.69[1.02-7.11]$ & 0.046 \\
\hline No & $35(56.5)$ & $9(31.0)$ & & & \\
\hline
\end{tabular}


Table 3 (continued)

\begin{tabular}{|c|c|c|c|c|c|}
\hline \multirow[t]{2}{*}{ Characteristics } & \multirow[t]{2}{*}{$\mathrm{CAP}(n=62)$} & \multirow[t]{2}{*}{ CAP+VRTI $(n=29)$} & \multirow[t]{2}{*}{$p$ value } & \multicolumn{2}{|c|}{$\begin{array}{l}\text { Multivariate logistic } \\
\text { regression analysis }\end{array}$} \\
\hline & & & & $\operatorname{adjOR}(95 \% \mathrm{CI})$ & $p$ value \\
\hline \multicolumn{6}{|l|}{ Bacteraemia, $n(\%)$} \\
\hline Yes & $5(8.1)$ & $1(3.4)$ & 0.66 & & \\
\hline No & $46(74.1)$ & $24(82.8)$ & & & \\
\hline Missing & $11(17.7)$ & $4(13.8)$ & & & \\
\hline \multicolumn{6}{|c|}{ Radiological pattern, $n(\%)$} \\
\hline Alveolar & $45(72.6)$ & $21(72.4)$ & 0.57 & & \\
\hline Interstitial & $4(6.6)$ & $0(0.0)$ & & & \\
\hline Cavitary & $1(1.6)$ & $0(0.0)$ & & & \\
\hline Alveolar-interstitial & $9(14.5)$ & $6(20.7)$ & & & \\
\hline Other & $3(4.8)$ & $2(6.9)$ & & & \\
\hline \multicolumn{6}{|l|}{ Pleural effusion, $n(\%)$} \\
\hline Yes & $12(19.4)$ & $6(20.7)$ & 1.0 & & \\
\hline No & $50(80.6)$ & $23(79.3)$ & & & \\
\hline \multicolumn{6}{|c|}{ Air bronchogram, $n(\%)$} \\
\hline Yes & $3(4.8)$ & $3(10.3)$ & 0.38 & & \\
\hline No & $59(95.2)$ & $26(89.7)$ & & & \\
\hline \multicolumn{6}{|c|}{ Time between onset of symptoms and hospital admission, days } \\
\hline Mean \pm SD & $4.6 \pm 6.0$ & $3.4 \pm 3.9$ & 0.32 & & \\
\hline \multicolumn{6}{|c|}{ Pre-admission antibiotic therapy, $n(\%)$} \\
\hline Yes & $22(35.5)$ & $2(6.9)$ & 0.004 & $0.14[0.03-0.67]$ & 0.014 \\
\hline No & $40(64.5)$ & $27(93.1)$ & & & \\
\hline \multicolumn{6}{|c|}{ In-hospital antibiotic therapy, days } \\
\hline Mean \pm SD & $12.3 \pm 4.9$ & $11.3 \pm 4.0$ & 0.34 & & \\
\hline
\end{tabular}

Adj OR, adjusted odds ratio; CAP, community-acquired pneumonia; CI, confidence interval; ICU, intensive care unit; PSI, pneumonia severity index; SD, standard deviation; VRTI, viral respiratory tract infection

\section{Discussion}

In the present study, we prospectively analysed the prevalence and the clinical impact of VRTIs on patients with CAP hospitalized at medical wards. VRTIs' prevalence rate we found was as high as $31.9 \%$ (95\% CI $22.3-41.4 \%$ ), but fortunately VRTIs did not negatively affect clinical outcome.

A recent meta-analysis reported a $22 \%$ (95\% CI 17-27\%) VRTIs' prevalence rate in adults with CAP that rose to $29 \%$ (95\% CI 25-34\%) including only studies where molecular assays were used [31]. Our data confirm that in a real-life setting, including a mixed population of immunocompetent and immunocompromised adults hospitalized for CAP, VRTIs are highly prevalent.

At admission, patients with VRTI had more frequently PSI score IV-IV than those without. Three previous studies (of whom two were retrospective) found an association between VRTIs and PSI class IV/V, but none of them reported on CURB-65 score [13, 25, 32]. Contrary to PSI score, we did not find any relationship between CURB-65 and VRTIs. Reasons why higher classes for risk of severe pneumonia at PSI but no at CURB-65 were associated with VRTI are unclear. One possible explanation might rely on the higher sensitivity of PSI compared to CURB-65 [33], even if guidelines do not recommend one score over another for patient's discharge [1].

Additionally, patients with VRTI received pre-admission antibiotic therapy less frequently than those without. This finding may be explained in two ways: first, local and national recommendations are against the use of any antibiotic at the onset of a clinically presumed viral respiratory syndrome; second, a viral respiratory syndrome may actually favour the subsequent onset of a CAP.

Interestingly, in our study CAP radiological features were not affected by the presence of VRTI. This is consistent with observations that, in some instance, viral and bacterial pneumonia may have similar radiological features [34]

It is worth noting that, in spite of higher PSI scores in presence of VRTIs, we found no association between VRTIs and need of antibiotic treatment escalation, ICU admission and risk of mortality. Other studies investigating clinical outcomes in the same setting found opposite results. Yoon 
et al. [25] found that preceding VRTIs do not affect mortality in adults with pneumococcal CAP, while Voiriot et al. [32] reported that mixed bacterial and viral infections are associated with hospital death and/or prolonged mechanical ventilation in ICU-admitted CAP patients. Moreover, some authors used different surrogate endpoints of clinical response, such as length of hospitalization or length of mechanical ventilation. However, these endpoints may be affected by a variety of factors, including the presence of any comorbidity and the development of superinfection, thus not sufficiently clarify the role of VRTIs. On the other hand, as escalation of antibiotic treatment is usually the consequence of lack of response to previous treatment, we evaluated the impact of VRTIs on the need of antibiotic escalation.

The interplay between virus and bacteria, spanning from the damage of respiratory mucosa to affecting the normal immune response, has been well described, in vitro and in vivo, for either influenza virus [35-37] or other viruses, in particular RSV and metapneumovirus [38, 39] In addition, beyond favouring bacterial infection, some respiratory viruses may per se cause pneumonia [40]. Thus, we stratified patients according to the supposed microbiological aetiology and we found that mixed and viral CAP had pneumonia severity at admission, radiological findings and outcomes similar to bacterial CAP. However, the viruses detected in the pharynx may represent only infection of the upper respiratory tract, while lower respiratory tract specimens may be more reflective of the pathogen causing pneumonia [40-42]. In our real-life cohort, bronchoalveolar lavage culture was performed only when clinically indicated. As only a few patients experienced clinical failure and required ICU admission or antibiotic escalation, invasive procedures were deemed unnecessary in the majority of cases. Additionally, $43 \%$ of patients included in our cohort had CAP of unknown aetiology, a finding that could be at least partially explained with previous at-home antibiotic treatment before specimens collection. The limited sample size of patients diagnosed with bacterial/viral/mixed CAP and the lack of lower respiratory tract sampling in almost all cases prevents any firm conclusion on the clinical presentation and outcome of CAP according to the aetiology and deserves further studies.

Influenza virus was the most frequent viral infection we found in our cohort. While the presence of VRTI did not impact on the TTA, negative PCR for Influenza virus was used for early antiviral treatment discontinuation. Indeed, current guidelines recommend universal empirical antiviral treatment in patients with influenza-like illness, whose clinical presentation (i.e. fever plus cough started within the last 10 days) overlaps with that of CAP [28]. On the other hand, VRTI identification was not useful to guide antibiotic treatment, as demonstrated by the lack of association with TTA.

Beyond the lack of low respiratory tract specimens, the other limitation of this study is that we enrolled both immunocompetent and immunosuppressed patients. As immunosuppression is a risk factor for more severe infections (depending on the type and intensity), our data may overestimate the risk of clinical failure. Of note, two out of three patients who died within 30 days from admission for CAP had concomitant immunosuppression.

In conclusion, in spite of high prevalence rates, VRTIs do not negatively affect the outcome of CAP. Further studies are needed to evaluate the clinical presentation and outcome of mixed and viral CAP with respect to bacterial ones in hospitalized patients who do not need intensive care.

Funding The authors declare no funding foundation.

\section{Compliance with ethical standards}

Conflict of interest The authors declare that they have no conflict of interest.

Ethical approval All procedures performed were in accordance with the ethical standards of the institutional and/or national research committee and with the 1964 Helsinki Declaration and its later amendments or comparable ethical standards. The study was approved by the Regional Ethics Committee (Regional Ethics Committee of Liguria Region, Registry Number 357RE62016).

Informed consent Participants signed specific informed consent.

\section{References}

1. Mandell LA, Wunderink RG, Anzueto A et al (2007) Infectious Diseases Society of America/American Thoracic Society consensus guidelines on the management of community-acquired pneumonia in adults. Clin Infect Dis 44(Suppl 2):S27-72. https://doi. org/10.1086/511159

2. File TM (2003) Community-acquired pneumonia. Lancet 362:1991-2001. https://doi.org/10.1016/S0140-6736(03)15021-0

3. Musher DM, Thorner AR (2015) Community-acquired pneumonia. N Engl J Med 372:294. https://doi.org/10.1056/NEJMc14143 06

4. Guest JF, Morris A (1997) Community-acquired pneumonia: the annual cost to the National Health Service in the UK. Eur Respir J 10:1530-1534. https://doi.org/10.1183/09031936.97.10071530

5. Arnold FW, Wiemken TL, Peyrani P et al (2013) Mortality differences among hospitalized patients with community-acquired pneumonia in three world regions: results from the CommunityAcquired Pneumonia Organization (CAPO) International Cohort Study. Respir Med 107:1101-1111. https://doi.org/10.1016/j. rmed.2013.04.003

6. van Gageldonk-Lafeber AB, Heijnen M-LA, Bartelds AIM et al (2005) A case-control study of acute respiratory tract infection in general practice patients in The Netherlands. Clin Infect Dis 41:490-497. https://doi.org/10.1086/431982

7. Tregoning JS, Schwarze J (2010) Respiratory viral infections in infants: causes, clinical symptoms, virology, and immunology. Clin Microbiol Rev 23:74-98. https://doi.org/10.1128/ CMR.00032-09 
8. Nicholson KG, Kent J, Hammersley V, Cancio E (1997) Acute viral infections of upper respiratory tract in elderly people living in the community: comparative, prospective, population based study of disease burden. BMJ 315:1060-1064. https://doi. org/10.1136/bmj.315.7115.1060

9. Lau SKP, Woo PCY, Yip CCY et al (2006) Coronavirus HKU1 and other coronavirus infections in Hong Kong. J Clin Microbiol 44:2063-2071. https://doi.org/10.1128/JCM.02614-05

10. Gorse GJ, O'Connor TZ, Hall SL et al (2009) Human coronavirus and acute respiratory illness in older adults with chronic obstructive pulmonary disease. J Infect Dis 199:847-857. https:// doi.org/10.1086/597122

11. Couch RB, Englund JA, Whimbey E (1997) Respiratory viral infections in immunocompetent and immunocompromised persons. Am J Med 102:2-9. 10.1016/s0002-9343(97)00003-x (discussion 25-26)

12. Berry M, Gamieldien J, Fielding BC (2015) Identification of new respiratory viruses in the new millennium. Viruses 7:996-1019. https://doi.org/10.3390/v7030996

13. Templeton KE, Scheltinga SA, Beersma MFC et al (2004) Rapid and sensitive method using multiplex real-time PCR for diagnosis of infections by influenza a and influenza B viruses, respiratory syncytial virus, and parainfluenza viruses $1,2,3$, and 4. J Clin Microbiol 42:1564-1569. https://doi.org/10.1128/ jcm.42.4.1564-1569.2004

14. van Elden LJR, van Kraaij MGJ, Nijhuis M et al (2002) Polymerase chain reaction is more sensitive than viral culture and antigen testing for the detection of respiratory viruses in adults with hematological cancer and pneumonia. Clin Infect Dis 34:177-183. https ://doi.org/10.1086/338238

15. Adcock PM, Stout GG, Hauck MA, Marshall GS (1997) Effect of rapid viral diagnosis on the management of children hospitalized with lower respiratory tract infection. Pediatr Infect Dis J 16:842-846. https://doi.org/10.1097/00006454-199709000-00005

16. Woo PC, Chiu SS, Seto WH, Peiris M (1997) Cost-effectiveness of rapid diagnosis of viral respiratory tract infections in pediatric patients. J Clin Microbiol 35:1579-1581

17. Burk M, El-Kersh K, Saad M et al (2016) Viral infection in community-acquired pneumonia: a systematic review and meta-analysis. Eur Respir Rev 25:178-188. https://doi.org/10.1183/16000 617.0076-2015

18. Kim PE, Musher DM, Glezen WP et al (1996) Association of invasive pneumococcal disease with season, atmospheric conditions, air pollution, and the isolation of respiratory viruses. Clin Infect Dis 22:100-106. https://doi.org/10.1093/clinids/22.1.100

19. Berendt RF, Long GG, Walker JS (1975) Influenza alone and in sequence with pneumonia due to Streptococcus pneumoniae in the squirrel monkey. J Infect Dis 132:689-693. https://doi. org/10.1093/infdis/132.6.689

20. Nickerson CL, Jakab GJ (1990) Pulmonary antibacterial defenses during mild and severe influenza virus infection. Infect Immun 58:2809-2814

21. Carson JL, Collier AM, Hu SS (1985) Acquired ciliary defects in nasal epithelium of children with acute viral upper respiratory infections. N Engl J Med 312:463-468. https://doi.org/10.1056/ NEJM198502213120802

22. McCullers JA (2006) Insights into the interaction between influenza virus and pneumococcus. Clin Microbiol Rev 19:571-582. https://doi.org/10.1128/CMR.00058-05

23. Peltola VT, McCullers JA (2004) Respiratory viruses predisposing to bacterial infections: role of neuraminidase. Pediatr Infect Dis J 23:S87-97. https://doi.org/10.1097/01.inf.0000108197.81270.35

24. Bisno AL, Griffin JP, Van Epps KA et al (1971) Pneumonia and Hong Kong influenza: a prospective study of the 1968-1969 epidemic. Am J Med Sci 261:251-263. https://doi.org/10.1097/00000 441-197105000-00004
25. Yoon YK, Yang KS, Sohn JW et al (2014) Impact of preceding respiratory viral infections on the clinical severity of patients with Pneumococcal pneumonia. Influenza Other Respir Viruses 8:549-556. https://doi.org/10.1111/irv.12265

26. Ampofo K, Bender J, Sheng X et al (2008) Seasonal invasive pneumococcal disease in children: role of preceding respiratory viral infection. Pediatrics 122:229-237. https://doi.org/10.1542/ peds.2007-3192

27. Strålin K, Törnqvist E, Kaltoft MS et al (2006) Etiologic diagnosis of adult bacterial pneumonia by culture and PCR applied to respiratory tract samples. J Clin Microbiol 44:643-645. https:// doi.org/10.1128/JCM.44.2.643-645.2006

28. Uyeki TM, Bernstein HH, Bradley JS et al (2019) Clinical Practice Guidelines by the Infectious Diseases Society of America: 2018 update on diagnosis, treatment, chemoprophylaxis, and institutional outbreak management of seasonal influenzaa. Clin Infect Dis 68:e1-e47. https://doi.org/10.1093/cid/ciy866

29. Farr BM, Sloman AJ, Fisch MJ (1991) Predicting death in patients hospitalized for community-acquired pneumonia. Ann Intern Med 115:428-436. https://doi.org/10.7326/0003-4819-115-6-428

30. Fine MJ, Auble TE, Yealy DM et al (1997) A prediction rule to identify low-risk patients with community-acquired pneumonia. N Engl J Med 336:243-250. https://doi.org/10.1056/NEJM199701 233360402

31. Alimi Y, Lim WS, Lansbury L et al (2017) Systematic review of respiratory viral pathogens identified in adults with communityacquired pneumonia in Europe. J Clin Virol 95:26-35. https://doi. org/10.1016/j.jcv.2017.07.019

32. Voiriot G, Visseaux B, Cohen J et al (2016) Viral-bacterial coinfection affects the presentation and alters the prognosis of severe community-acquired pneumonia. Crit Care 20:375. https://doi. org/10.1186/s13054-016-1517-9

33. Aujesky D, Auble TE, Yealy DM et al (2005) Prospective comparison of three validated prediction rules for prognosis in community-acquired pneumonia. Am J Med 118:384-392. https://doi. org/10.1016/j.amjmed.2005.01.006

34. Tan D, Fu Y, Xu J et al (2016) Severe adenovirus communityacquired pneumonia in immunocompetent adults: chest radiographic and CT findings. J Thorac Dis 8:848-854. https://doi. org/10.21037/jtd.2016.03.38

35. McCullers JA (2014) The co-pathogenesis of influenza viruses with bacteria in the lung. Nat Rev Microbiol 12:252-262. https:// doi.org/10.1038/nrmicro3231

36. Smith AM, Adler FR, Ribeiro RM et al (2013) Kinetics of coinfection with influenza A virus and Streptococcus pneumoniae. PLoS Pathog 9:e1003238. https://doi.org/10.1371/journ al.ppat. 1003238

37. Kash JC, Walters K-A, Davis AS et al (2011) Lethal synergism of 2009 pandemic H1N1 influenza virus and Streptococcus pneumoniae coinfection is associated with loss of murine lung repair responses. MBio. https://doi.org/10.1128/mBio.00172-11

38. Smith CM, Sandrini S, Datta S et al (2014) Respiratory syncytial virus increases the virulence of Streptococcus pneumoniae by binding to penicillin binding protein 1a. A new paradigm in respiratory infection. Am J Respir Crit Care Med 190:196-207. https://doi.org/10.1164/rccm.201311-2110OC

39. Lai S-H, Liao S-L, Wong K-S, Lin T-Y (2016) Preceding human metapneumovirus infection increases adherence of Streptococcus pneumoniae and severity of murine Pneumococcal pneumonia. J Microbiol Immunol Infect 49:216-224. https://doi.org/10.1016/j. jmii.2014.04.008

40. Jartti T, Jartti L, Peltola V et al (2008) Identification of respiratory viruses in asymptomatic subjects: asymptomatic respiratory viral infections. Pediatr Infect Dis J 27:1103-1107. https://doi. org/10.1097/INF.0b013e31817e695d 
41. Cunha CB (2016) Relation of diagnostic accuracy of viral respiratory polymerase chain reaction to specimen number and source in severe adenovirus pneumonia: antimicrobial stewardship implications. Infect Control Hosp Epidemiol 37:1127-1129. https://doi. org/10.1017/ice.2016.144

42. López Roa P, Rodríguez-Sánchez B, Catalán P et al (2012) Diagnosis of influenza in intensive care units: lower respiratory tract samples are better than nose-throat swabs. Am J Respir Crit Care Med 186:929-930. https://doi.org/10.1164/ajrccm.186.9.929

Publisher's Note Springer Nature remains neutral with regard to jurisdictional claims in published maps and institutional affiliations. 